\title{
On the Ideological and Political Education of Dragon Boat Culture in
}

\section{Colleges and Universities}

\author{
Zhi-quan $\mathrm{An}^{1, \mathrm{a}}$, Meng Li ${ }^{1, \mathrm{~b}}$, Pei-wen Guan ${ }^{1, \mathrm{c}}$, Kai Wang ${ }^{1, \mathrm{~d}^{*}}$ \\ ${ }^{1}$ Beihua University ,Jilin, China \\ *Corresponding author
}

Key words: colleges and universities; dragon boat culture; ideological and political education; role

\begin{abstract}
.
The dragon boat culture is an innovative university culture that is newly developing as an ancient tradition,it is the embodiment of the national spirit,sports competitions and festival celebrations,it also has injected new vitality to the extracurricular games,campus activities an athletic competitions,etc...It is an important way for enhancing the comprehensive quality and moral cultivation of students, promoting the Chinese traditional cultural heritage and enriching campus cultural construction to make the Chinese tradition inherit in modern society and the dragon boat culture develop in universities, and meanwhile it plays an important role in the process of students' ideological and political education.

With the increasing social influence of dragon boat culture and the number of competitions, more and more people have realized the importance of dragon boat culture as well as its deep spiritual and cultural connotations. The integration of dragon boat culture into colleges and universities will make itself more popular with college students, it will ,together with the campus culture, bring great impetus to promote the traditional culture inheritance and ideological and political cultivation.
\end{abstract}

\section{The connotation of dragon boat culture}

The ancient meaning of dragon boat culture. The dragon boat culture is mainly embodied in the dragon boat festival and the related activities, things, customs and folk origins, it is a classical culture emerges in folks, as well as a kind of totem and hero worship culture . The dragon boat festival is also called the dragon boat race, dragon boat rowing ,dragon boat competition,it is a kind of mass entertainment with rich traditional folk culture and from the origin story of dragon boat race ,sacrificial process dragon boat shape and other aspects, we can still see the strong national colors, The reason why the dragon boat festival has a long history and keeps unfading is that it contains one image of “dragon"and the other"boat”. The dragon is a sacred representative of many animals and celestial phenomena collected by the ancient Chinese.It is a national totem and cultural symbol of the Chinese descendant.Dragon culture is an important element in the culture of dragon boat,while dragon boat culture is one expression of dragon culture,cultural activities related to dragon is the national cohesion and centripetal force of spirit to infect and arouse every Chinese people.The boat should have been a kind of water transport ,the dragon boat race originated from the work and life on the water of different ethnic groups.In the course of historical development, combined with $\mathrm{Qu}$ Yuan, poet of Chu, in the spring and Autumn period and the Warring States period, it became the activity of remembering heroes and representing the customs of the Dragon 
Boat Festival. Qu Yuan himself is a patriotic poet, and people's memorial ceremony to him is the embodiment of the spirit of patriotism, which is the identity and admiration of heroes' noble spirit and character. In the course of the dragon boat race, it is the best interpretation of the spirit of collectivism that people go forward courageously, unite, unite as one,work hard together and make concerted effort. The spirit of patriotism and the spirit of collectivism are the two main ideas of dragon boat culture.

The contemporary social value of dragon boat culture. The contemporary social value of dragon boat culture is mainly manifested in the aspects of cultural education, physical, health, recreation and leisure. The value of cultural education is an important spiritual value of dragon boat culture. The dragon boat culture itself is the carrier of Chinese traditional culture. It has communicated patriotism and collectivism spirit for thousands of years, and has made important contributions to the development of Chinese culture. For thousands of years, the scholars who have sung and poetized for the dragon boat race is even more unusual, which describes a warm festive atmosphere and shows the culture connotation as well as leaves a priceless cultural wealth for future generations., in poetries, paintings, songs and other aspects. Dragon boat culture has been internationalized, which promotes the exchange of Chinese culture with other cultures, and promotes the friendship between the Chinese people and people of all countries. The physical health value is the embodiment of dragon boat movement, and it is also the most important social value of dragon boat. Dragon boat race has both the health function of physical exercise and the competitive role of competition. The dragon boat race continues to develop, and the number of the matches continues to increase, the status of the dragon boat culture continues to rise, and its physical value will also be greatly enhanced. The recreation part is the embodiment of Dragon Boat Festival ornamental value, which is the largest value of people's direct experience. Whether in ancient or modern society, where there are dragon boat races, there will be a large number of people to watch. Dragon boat racing greatly mobilizes and infects the audience for its strong ornamental value and popularity,which encourages the broad masses to love to see,actively take part in and entertainment their body and mind.

\section{The educational function of dragon boat culture in Universities}

Promote the comprehensive quality and moral cultivation of students. The national, collective, competitive and entertaining features of dragon boat culture play an active role in training, the correct outlooks world, life and values of the integrated talents. The dragon boat race use the sports way to get rid of the inherent form of ideological and political education, in the practice of team cooperation, it can not only cultivate a fair, just and open competitive sports spirit, put also can harvest the socialist spirit of solidarity and friendship, dedication and collective honor, realize the function of ideological and political education, and enhance the college students' ideological and moral realm. It makes for expanding the comprehensive quality, creating a positive spirit, cultivating innovative talents needed by the society, and it is the enrichment and supplement of ideological and political education in addition to professional academic study, and the innovation practice of quality education implement. College students have good character and consciousness, and they will fully understand and support the construction of socialist culture.

Promote the inheritance of our national traditional culture. In the long course of the past, dragon boat culture has been continuously developed and combined with colleges and universities. Colleges and universities are the main place for cultivating young talents of society, and they have the need of Ideological and political education for college students. In the process of exploring traditional culture resources, we draw new strength from the Chinese traditional dragon boat, the 
combination of the dragon boat culture with the university is integration of the old and the young, the cultural heritage and innovation, as well as the development and improvement of the ideological and political education. Most of the modern students indulge in the Internet and gradually forget the ancient excellent cultural heritage. The popularity of dragon boat culture among college students is the return of the essence of ancient thought. The combination of the traditional culture and national sports , can pull the students closely to traditional culture in practice, deepen the students' understanding and sympathy of totem and hero worship culture contained in the dragon boat. In sports, influenced and infected by ancient heroes in dragon boat culture, students' national feelings and patriotism, team consciousness and collectivism spirit can be aroused in collective struggle. Nurture students to create a subtle sense of national identity and cohesion, logical inherit Chinese tradition and culture.

Enrich the construction of multicultural Campus culture. The Construction of diversified campus cultural activities is an important part of Ideological and political education in Colleges and universities. At present, the construction of dragon boat culture on campus has three major carriers: sports platform, club platform and social promotion platform. The construction of sports platform refers to schools' organization of Dragon Boat Races, to attract and promote college students to participate in or watch, and promote the spread of dragon boat culture among the youth. The platform of club activities refers to the group organization of students concerned with dragon boat culture in the original community system,it can be a research class, an interest class or a sport class. Independent research and related activities held by students will help stimulate the enthusiasm of dragon boat culture and deepen the understanding it. Social promotion platform is that colleges and universities can set up a dedicated dragon boat team to participate in social events, in order to promote the dragon boat culture of the school, and demonstrate its Dragon Boat strength. While promoting the dragon boat culture for the community, it will promote the Dragon Boat enthusiasm of the whole society. The establishment of related associations of dragon boat culture can improve and perfect the categories and extracurricular activities of college associations, so as to enrich the campus cultural construction and diversify it. Through the independent communication, organization and management of the students, the enthusiasm and participation of the students in the dragon boat culture will be fully mobilized, which will help the students to improve their autonomy. At the same time, dragon boat culture and campus culture fuse and interact with each other. which can create a better campus atmosphere from the ideological level, build a unique cultural atmosphere and, in politics, match the socialist moral system.

\section{Acknowledgement}

This paper was supported by Scientific and Technological Planning Project of Beihua Universi ty (No.YB201622 and No.202116168) and the Beihua university 2017 college students' innovative entrepreneurial training plan.

\section{Reference:}

[1] Wu Guangjin, Qin Tokumasu. [J]. connotation of dragon boat culture and contemporary value of Heilongjiang national series, 2010, (06): 141-144

[2] Han Zhichao. Construction of evaluation index system of dragon boat culture on campus of College [D]. Liaocheng University, 2015

[3] Luo Lei. Analysis of the role of Dragon Boat Sports in the process of dragon boat culture 
succession [J]. contemporary educational practice and teaching research, 2016, (04): 271

[4] Wu Wu, Zhang Jialin, Lu Peng. Construction of University dragon boat movement and campus sports culture [J]. Journal of Inner Mongolia Normal University (EDUCATION SCIENCE EDITION), 2010, (09): 147-148

[5], Wang Hangdong, Zhang Dianliang. New thoughts on the origin and function of dragon boat culture [J]. Journal of Guangzhou Institute of navigation, 2014, (04): 38-40 